5 Buchwald HJ, Müller A, Kampmeier J, Lang GK. Optical coherence tomography versus ultrasound biomicroscopy of conjunctival and eyelid lesions. Klin Monatsbl Augenheilkd 2003; 220: 822-829.

Z Sbeity', S Dorairaj1,2, S McCormick ${ }^{3}$, J Liebmann ${ }^{4}$ and R Ritch ${ }^{1,5}$

${ }^{1}$ Einhorn Clinical Research Center, New York Eye

and Ear Infirmary, New York, NY, USA

${ }^{2}$ Department of Surgery, Beth Israel Medical

Center, New York, NY, USA

${ }^{3}$ Department of Pathology and laboratory

Medicine, New York Eye and Ear Infirmary, New

York, NY, USA

${ }^{4}$ Department of Ophthalmology, School of Medicine, New York University, New York, NY, USA

${ }^{5}$ Department of Ophthalmology, New York

Medical College, Valhalla, NY, USA

E-mail: ritchmd@earthlink.net

Eye (2009) 23, 489-491; doi:10.1038/eye.2008.46; published online 14 March 2008

\section{Sir, \\ Pain response and follow-up of patients undergoing panretinal laser photocoagulation (PRP) with reduced exposure times}

I read with interest the paper by Al-Hussainy et al. ${ }^{1}$ In their paper, the authors concluded that reducing the exposure time and increasing the laser power while performing PRP can reduce pain significantly without compromising the long-term results of the treatment.

It has been our experience that using scatter retinal laser application with shorter duration setting, as described by the author, yields uneven and much smaller sized scars than the traditionally used longer duration laser setting (the scars have less than intended treatment spot size and with larger untreated retina in between). This can be explained by both insufficient time available for heat conduction into surrounding tissue to cause thermal damage and the Gaussian distribution of the energy across laser beam. ${ }^{2}$ Additionally, it can be calculated from data provided by the authors that with reduced exposure setting, the mean laser energy necessary to achieve visible retinal reaction was much less $(0.02 \mathrm{~ms} \times 489 \mathrm{~mW}=9.78 \mathrm{~mJ}$ vs $0.1 \mathrm{~ms} \times 178 \mathrm{~mW}=$ $17.8 \mathrm{~mJ})$ and, hence, expectedly lesser associated tissue damage and subsequent scaring.

Although the immediate visible retinal burns were apparently similar, the authors failed to mention the difference in the scar appearances between the groups in their study. In our experience, spaced smaller retinal scars produced by shorter duration laser setting are usually indicative of inadequate treatment and necessitates further laser application to control the proliferative process.

As the end point of their study has not been clarified, it is difficult to gain any knowledge regarding the time scale as well as the number of the sessions that were required to achieve regression of neovasculrization in their series and conclude effectiveness of their setting, compared with any published data.
Finally, their treatment setting using Volks lens, $300-\mu \mathrm{m}$ spot size and high power requirement (mean 0.47 $\mathrm{W}$, no SD was mentioned) is likely to breach laser safety to the anterior segment, where the laser energy fluence is much higher than the retinal plane due to smaller laser beam size at the corneal plane. ${ }^{3}$

\section{References}

1 Al-Hussainy S, Dodson PM, Gibson JM. Pain response and followup of patients undergoing panretinal laser photocoagulation with reduced exposure times. Eye 2008; 22: 96-99.

2 Walsh Jr JT, Flotte TJ, Anderson RR, Deutsch TF. Pulsed CO2 laser tissue ablation: effect of tissue type and pulse duration on thermal damage. Lasers Surg Med 1988; 8(2): 108-118.

3 Shiraki K, Moriwaki M, Kohno T, Yanagihara N, Miki T. Inadvertent corneal burn by using indirect wide-field contact lenses and different laser beam delivery systems during experimental fundus photocoagulation. Lasers Surg Med 2000; 27(1): 43-48.

\section{A Toufeeq}

Eye Department, Wycombe Hospital, High

Wycombe, Buckinghamshire, England

E-mail: a.toufeeq@ntlworld.com

Eye (2009) 23, 491; doi:10.1038/eye.2008.111; published online 18 April 2008

Sir,

Functioning avascular retinae - a report of two siblings Complete absence of retinal vasculature is extremely rare; to date there have been four such reports published. ${ }^{1,2}$ It has been previously assumed that such an anomaly necessarily involves a complete lack of vision. We present two siblings who, despite having complete retinal vessel absence, have useful vision. To the best of the authors' knowledge, these are the first avascular, seeing retinae to be described.

\section{Case report}

Two sisters, aged three and five (AA, SA) of consanguineous parents, presented with poorly controlled congenital glaucoma. AA had a right phthisical eye following previous surgery and uncontrolled glaucoma in the left. She demonstrated a degraded electroretinogram (ERG) in the right eye (Figure 1); no responses were obtained from the phthisical left eye. No consistent visual-evoked potentials (VEP) were recorded, though she had her eyes closed. AA had a right vitreolensectomy with control of glaucoma with combined dorzolamide and timolol, and bimatoprost. SA had uncontrolled glaucoma and dense cataract on the right with moderately controlled glaucoma in the fellow eye. She demonstrated normal ERGs in the right eye but no consistent responses in the left. Flash VEPs were recorded from both eyes (Figure 1). SA underwent combined left trabeculectomy and trabeculotomy with mitomycin $\mathrm{C}$, with subsequent lensectomy. The right eye glaucoma was controlled topically as for AA. Both children had microspherophakia with marked iris hypoplasia and 